\title{
The assessment of a micro-grid operation under optimal planning of Electric Energy Storage units: RSE's case study
}

\author{
Vardanyan, Yelena; Verga, Maurizio; Lazzari, Riccardo; Pendieu, Marcel K.; Madsen, Henrik
}

Published in:

Proceedings of 2019 IEEE PES Asia-Pacific Power and Energy Engineering Conference,

Link to article, DOI:

10.1109/appeec45492.2019.8994459

Publication date:

2019

Document Version

Peer reviewed version

Link back to DTU Orbit

Citation (APA):

Vardanyan, Y., Verga, M., Lazzari, R., Pendieu, M. K., \& Madsen, H. (2019). The assessment of a micro-grid operation under optimal planning of Electric Energy Storage units: RSE's case study. In Proceedings of 2019 IEEE PES Asia-Pacific Power and Energy Engineering Conference, (pp. 1-5). IEEE. https://doi.org/10.1109/appeec45492.2019.8994459

\section{General rights}

Copyright and moral rights for the publications made accessible in the public portal are retained by the authors and/or other copyright owners and it is a condition of accessing publications that users recognise and abide by the legal requirements associated with these rights.

- Users may download and print one copy of any publication from the public portal for the purpose of private study or research.

- You may not further distribute the material or use it for any profit-making activity or commercial gain

- You may freely distribute the URL identifying the publication in the public portal 


\title{
The assessment of a micro-grid operation under optimal planning of Electric Energy Storage units: RSE's case study
}

\author{
Yelena Vardanyan*, Maurizio Verga ${ }^{\dagger}$, Riccardo Lazzari ${ }^{\ddagger}$ Marcel K. Pendieu ${ }^{\S}$ and Henrik Madsen $₫$ \\ $*$ DTU Compute, Technical University of Denmark \\ $\dagger \ddagger \S$ Materials and Generation Technologies Department, Ricerca sul Sistema Energetico - RSE SpA \\ Email: *yeva@dtu.dk, ${ }^{\dagger}$ Maurizio.Verga@ rse-web.it, ${ }^{\ddagger}$ Riccardo.Lazzari@ rse-web.it, ${ }^{\S}$ marcel.pendieukwaye@ @ rse-web.it \\ Ihmad@dtu.dk
}

\begin{abstract}
The EU is committed to reducing greenhouse gas emissions to $80-95 \%$ below 1990 levels by 2050 . To accomplish this goal the share of renewable energy sources have to increase significantly. Challenges related to keeping a high security of supply have raised while the share of intermittent renewable electricity generation is increasing. The increasing level of RES production leads to higher volatility in market prices. The main challenges lay within the modeling and simulation of the random variables. Therefore, the assessment of the operation of the entire micro-grid should be studied while constructing different test scenarios under uncertainty of the market prices and micro-grid configuration. This paper constructs different tests to investigate the integration of Electric Energy Storage unit technologies in a micro-grid. The assessment of the impact on the micro-grid, like congestion or voltage problem, are analyzed when the EES units are owned by a separate business entity called aggregator or a grid owner.
\end{abstract}

Index-terms: EES units, aggregator, micro-grid.

\section{NOMENCLATURE}

\section{A. Indices}

$\mathrm{k} \quad$ index for storages, $k=1, \ldots, K$;

$\mathrm{t}$ planning periods, $t=1, \ldots, T$;

\section{B. Parameters}

$\bar{P}_{k} / \underline{P}_{k} \quad$ Max/Min storage rate of disch./charge ;

$\bar{E}_{k} \quad$ Max. capacity of a storage;

$\bar{\gamma}_{k} / \underline{\gamma}_{k} \quad$ Scalar to calculate $\max / \min$ SoC ;

$\eta_{k}^{c h} / \eta_{k}^{d c h} \quad$ Charging/discharging efficiency of a storage;

$\eta_{k}^{r} \quad$ Round trip efficiency;

$\Delta t \quad$ time duration of each time step;

$S o C_{k, t=0} \quad$ Starting storage level;

$S o C_{k}^{e n d} \quad$ Storage level at the end of the day;

$\lambda_{s, t} \quad$ Market price scenarios;

$c_{t} \quad$ Aggregator's offer to storage owner;

$c_{k}^{c a p} \quad$ Capital cost of a storage;

$\mu_{k} \quad$ The slope of the linear approximation of the battery life as a function of the cycles;

$A_{s, k, t} \quad$ Availability matrix ;

$D_{s, k, t} \quad$ Average hourly driving distance;

$\eta_{k}^{d r} \quad$ Driving efficiency of a mobile storage;
C. Variables $p_{k, t}^{c h} / p_{k, t}^{d c h} \quad$ Charge/discharge level for $k^{t h}$ storage; $S_{0} C_{k, t}^{B} \quad$ Storage level at the end of time step $t$; $u_{k, t} \quad$ binary variable;

\section{INTRODUCTION}

The RES (Renewable Energy Sources) share in the power system is growing notably. Predictions, as well as EU targets 2030, 2050 [1], indicate that this growth will keep on increasing in the future. In addition, the RES (wind, solar, etc.) prediction techniques are not accurate enough to consider power production variations, and therefore huge unpredicted RES power production variations might happen in the power system in the near future. These variations must be handled in an optimal way. Some conventional generation units and demand response must be used to compensate RES power production variations in the power system and in this way, maintain the balance between production and consumption.

One way to support the grid is to enable the aggregation of the smaller resources to participate in the market. Recently, European electricity markets, particularly Nordic electricity market, are discussing about a new market entity called a third party aggregator [2].

Worldwide stationary and mobile Electric Energy Storage (EES) penetration are increasing significantly [3]. Therefore, there is a huge potential using stationary and mobile storages to assist the electric power grid. Under the smart grid concept, an EES aggregator will participate in energy markets on behalf of the EES owner, aiming to maximize its profit. Stationary and mobile storages can act as generators or consumers while interacting with the electric grid. As a market entity, the EES unit aggregator aims at buying/selling the electric power at the lowest/highest possible price [4].

Authors in all mentioned references study standalone cases to validate the developed models. In the similar way, the developed approach in [5] is applied to derive a bidding discharge/charge curve of an EES unit aggregator managing large number of stationary and mobile EES units without considering any micro-grid. Therefore, real case studies, which 
illustrate and analyse the simulation results of an EES unit aggregation models on a grid formed by different components like generation, loads, storage devices and so on, will bring an additional value.

In addition, the increasing level of RES production leads to higher volatility in market prices. The main challenges lay within the modeling and simulation of the random variables. Hence, the assessment of the operation of the entire micro-grid should be studied while constructing different test scenarios when 1) the EES units are owned by an aggregator or 2) by the grid operator.

Therefore, first, the model developed in [5] is used to generate optimal charge/discharge planning of EES units. Then, different tests have been carried out using RSE's microgrid infrastructure, considering different market price scenarios and assuming 1) the EES units in the micro-grid are owned by an aggregator who aims to fulfil its economic incentives 2) the EES units are owned by the grid operator who aims to support the grid needs. Finally, the behaviour of the micro-grid is studied by investigating the executed test results.

The paper is structured as follows. Section III describes the executed tests and experiments. Section IV discusses the results of the tests and in Section V the conclusion is drawn.

\section{EXECUTED TESTS AND EXPERIMENTS}

\section{A. RSE micro-grid configuration}

The RSE DER-TF (Distributed Energy Resources Test Facility) [6] is an infrastructure available for researchers in order to develop and test Smart Grid and Microgrid concepts, including management and control optimization, advanced power system architectures, DER and storages integration, electric mobility. RSE DER-TF is a real hybrid AC-DC low voltage micro-grid that interconnects different generators, storage systems and loads to develop studies and experimentations on DERs and micro-grids. The Facility extends over an area of about $20000 \mathrm{~m}^{2}$, is interconnected to the MV Grid by means of a $800 \mathrm{kVA}$ dedicated transformer and is able to operate in grid-connected or in islanded mode thanks to grid-forming converters. The micro-grid is configurable at the interconnection board in order to obtain different grid topologies and the feeders can be extended till one kilometer. The micro-grid is equipped with power quality analyzer and phaser measurement units, set up to collect and analyze the experimental data derived from the field test. A Supervision and Control system has been developed in order to monitor and control all installed resources.

Fig. 1 illustrates the RSE's micro-grid configuration ('benchmark' configuration in our experiments). All the components are connected directly to the main bus in a radial configuration. According to the Fig. 1, during the tests, the main components of the micro-grid configuration were four EES units, the PV plant, the wind turbine and the load. The main specifications related to the EES units integrated in the RSE's micro-grid are summarized in Table I.
TABLE I: EES unit specifications

\begin{tabular}{c|c|c|c|c}
\hline & Lithium & Lead & NaNiCl & Redox \\
\hline $\bar{E}_{k}(\mathrm{kwh})$ & 32 & 35 & 67 & 90 \\
\hline $\bar{P}_{k}^{c h}(\mathrm{kw})$ & -30 & -5 & -18 & -20 \\
\hline $\bar{P}_{k}^{d c h}(\mathrm{kw})$ & 30 & 15 & 18 & 25 \\
\hline$\eta_{k}^{r}(\%)$ & $92-98$ & $88-94$ & $90-96$ & $68-72$ \\
\hline $\bar{\gamma}_{k}$ & 0.8 & 0.8 & 0.8 & 0.8 \\
\hline $\bar{\gamma}_{k}$ & 0.2 & 0.2 & 0.2 & 0.2 \\
\hline$c_{k}^{c a p}(€)$ & 31000 & 22250 & 50020 & 97000 \\
\hline$\mu_{k}$ & -0.0013 & -0.0013 & -0.0013 & -0.0013 \\
\hline
\end{tabular}

Normally the micro-grid is operated in radial configuration Fig. 1. However, in case of line fault or maintenance, the micro-grid configuration can be modified ('modified' configuration in our experiments). In this situation the overall micro-grid could be weaker than in a radial configuration. To verify that, also in this case contingency doesn't happen, we realized some tests with a modified (weak) configuration of the RSE's micro-grid. The weak configuration has been obtained connecting the main components to a single feeder, inserting line extensions with different length between them.

\section{B. Aggregation model}

The aggregator solves a linear program stated in (1)-(5) to derive optimal charge/discharge plans for its EES units.

$$
\begin{gathered}
\operatorname{Max} . \sum_{t, k}\left[\left(\lambda_{t} p_{k, t}^{d c h} \Delta t-c_{t} \frac{p_{k, t}^{d c h}}{\eta_{k}^{d c h}} \Delta t-\left|\frac{\mu_{k}}{100}\right| \frac{c_{k}^{c a p}}{\bar{E}_{k}} p_{k, t}^{d c h} \Delta t\right)\right. \\
\left.-\left(\lambda_{t} p_{k, t}^{c h} \Delta t-c_{t} \eta_{k}^{d c h} p_{k, t}^{c h} \Delta t+\left|\frac{\mu_{k}}{100}\right| \frac{c_{k}^{c a p}}{\bar{E}_{k}} p_{k, t}^{c h} \Delta t\right)\right]
\end{gathered}
$$

The first line in (1) formulates the aggregators profit (revenue minus cost) while discharging. The second line in (1) expresses the aggregators profit (revenue minus cost) when offering charging. In (1) the last term in both lines model the battery degradation cost.

The energy balance constraint can be modeled as:

$$
\begin{aligned}
& S o C_{k, t}=S o C_{k, t-1}+\left[p_{k, t}^{c h} \eta_{k}^{c h} \Delta t-\frac{p_{k, t}^{d c h}}{\eta_{k}^{d c h}} \Delta t\right] A_{k, t} \\
& -D_{k, t} \eta_{k}^{d r}\left(1-A_{k, t}\right)
\end{aligned}
$$

Equation (2) states that for each hour the new energy level is equal to its old value plus energy inflow minus energy outflow. Please note that, (2) allows modeling both stationary and mobile storages. For stationary storages, the availability matrix $A_{k, t}$ is always 1 ; hence the last term which is energy spend on driving purposes vanishes. For mobile storages the availability matrix is either 0 or 1 depending on weather the mobile storage is available or on a trip.

The constraint (3) bounds the storage content by its minimum and maximum levels.

$$
\underline{\gamma}_{k} \bar{E}_{k} \leq S o C_{k, t} \leq \bar{\gamma}_{k} \bar{E}_{k}
$$




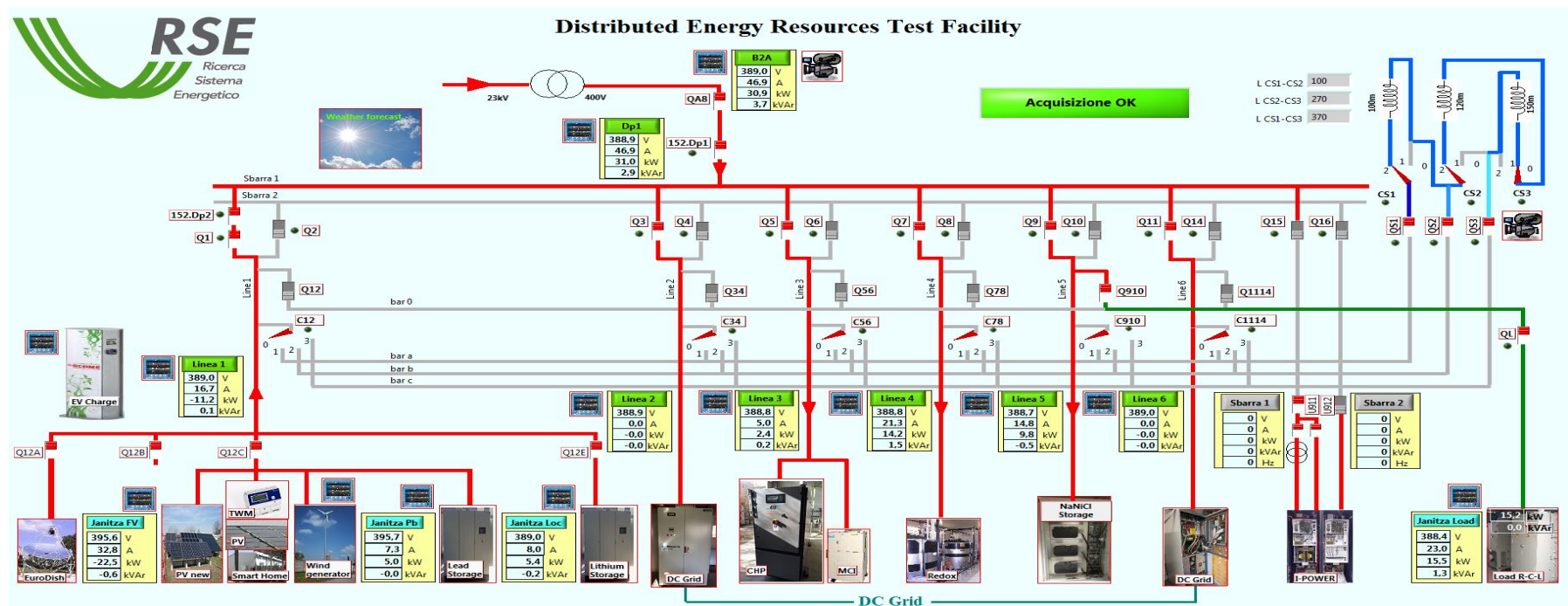

Fig. 1: RSE micro-grid configuration.

The constraints (4) and (5) define charge/discharge power level based on the maximum and minimum device discharge/charge capacity. Note that if the device is not available the power level will be forced to be 0 according to (4) and (5). In addition, an EES unit will either charge or discharge for each time step by introducing binary variable $u_{k, t}$ in (4) and (5).

$$
\begin{aligned}
& A_{k, t} \underline{P}_{k}^{d c h} u_{k, t} \leq p_{k, t}^{d c h} \leq \bar{P}_{k}^{d c h} u_{k, t} A_{k, t} \\
& A_{k, t} \underline{P}_{k}^{c h}\left(1-u_{k, t}\right) \leq p_{k, t}^{B c h} \leq \bar{P}_{k}^{c h}\left(1-u_{k, t}\right) A_{k, t}
\end{aligned}
$$

\section{Market Price scenarios}

Studies in [7] show that the Markov-based HW model is one of the best performing predicting tool for electricity market prices. Accordingly, the market prices are predicted using the standard HW model as in [7]. For that purpose historical data related to market prices reported in Nord Pool website [8] is used. Then, the market price scenarios are generated considering the expected values, the variances of market prices and assuming normal distribution.

\section{Test Set-up}

Using RSE's micro-grid benchmark configuration depicted in Fig. 1 two tests are launched (Test 1 and 2). For each test the procedure is the following: 1) deriving hourly optimal charge/discharge plans for EES units for an example market price scenario using optimization model summarized in (1)-(5) and 2) operating the whole micro-grid with the optimal charge/discharge plans calculated in step 1). Using RSE's micro-grid modified configuration another two tests are conducted (Test 3 and 4). For the Test 3 charge/discharge plans for EES units are obtained from the optimization model (the EES units are owned by an aggregator). However, the storage units are allowed to support freely the micro-grid needs for the Test 4 (the EES units are owned by the grid operator).

The constructed tests are summarized in Table II.
TABLE II: Summary of the constructed tests

\begin{tabular}{c|c|c|c|c}
\hline & $\begin{array}{c}\text { Micro-grid } \\
\text { configuration }\end{array}$ & $\begin{array}{c}\text { Market price } \\
\text { scenario }\end{array}$ & $\begin{array}{c}\text { Operation of } \\
\text { the EES units }\end{array}$ & $\begin{array}{c}\text { EES unit } \\
\text { owner }\end{array}$ \\
\hline Test 1 & Benchmark & scenario 1 & optimal & Agg-tor \\
\hline Test 2 & Benchmark & scenario 2 & optimal & Agg-tor \\
\hline Test 3 & Modified & scenario 1 & optimal & Agg-tor \\
\hline Test 4 & Modified & - & Not optimal & Grid op-tor \\
\hline
\end{tabular}

\section{E. Data Management}

The communication between the EES unit aggregation model, coded in GAMS, and the RSE test environment have been conducted in the following way. First, the optimization model have been simulated with corresponding input data in GAMS. Then the derived optimal charge/discharge plans for the EES units have been manually transferred as input data to the micro-grid test environment. Finally, the corresponding test has been launched.

\section{RESULTS}

\section{A. Tests constructed on the RSE's benchmark configuration:}

Test 1: Results from RSE's micro-grid benchmark configuration, while optimal operating the EES units with market price scenario 1, are discussed below. Fig. 2 depicts the optimal charge/discharge power profiles for EES units resulting from the optimization model.

Accordingly, Fig. 3 and Fig. 4 are the voltages and the frequencies of the micro-grid components. Taking into consideration that the voltage and frequency limits for RSE's microgrid components are nominal voltage $\pm 10 \%$ of nominal voltage $(400 \pm 40 \mathrm{~V})$ and nominal frequency $\pm 5 \%$ of nominal frequency $(50 \pm 2.5 \mathrm{~Hz})$ respectively, it is easy to observe that there is not any issue related to the voltages and the frequencies of micro-grid components.

Test 2: The discussion of the results from RSE's micro-grid benchmark configuration, while optimal operating the EES units with market price scenario 2, are presented below. Fig. 


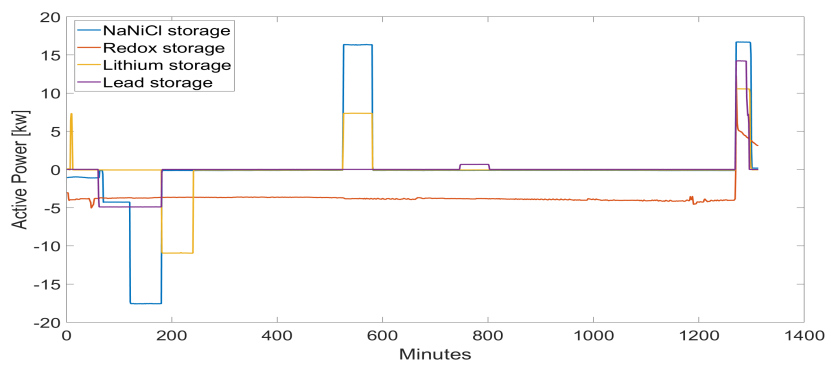

Fig. 2: Optimal charge/discharge plans for the storage units resulted from the optimization problem; scenario 1 . The positive/negative active power represents discharge/charge volumes respectively.

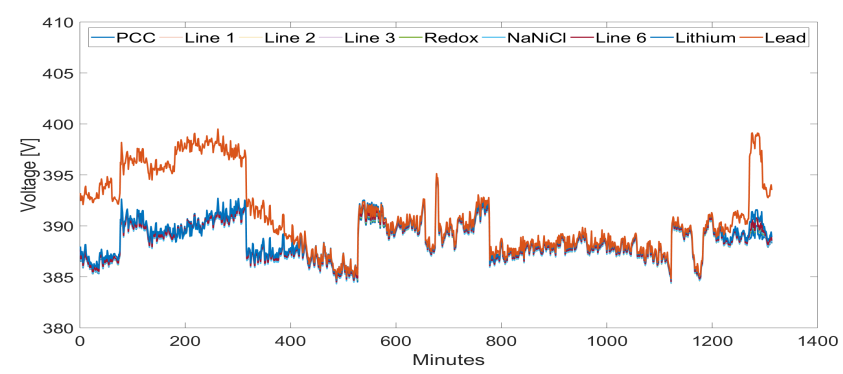

Fig. 3: Micro-grid component voltages for Test 1

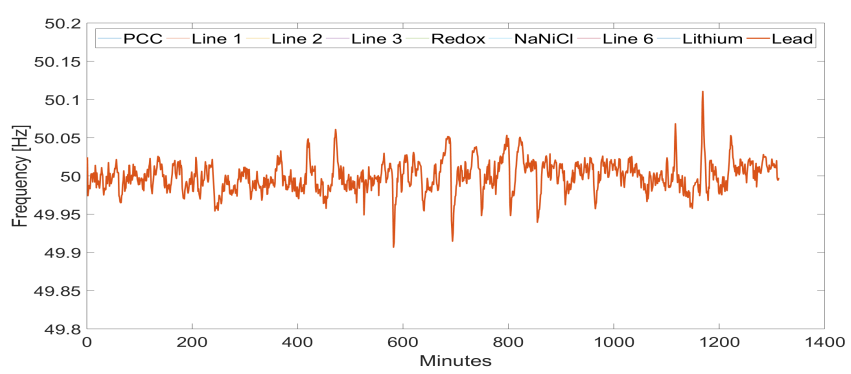

Fig. 4: Micro-grid component frequencies for Test 1.

5 depicts the optimal charge/discharge plans for EES units resulting from the optimization model.

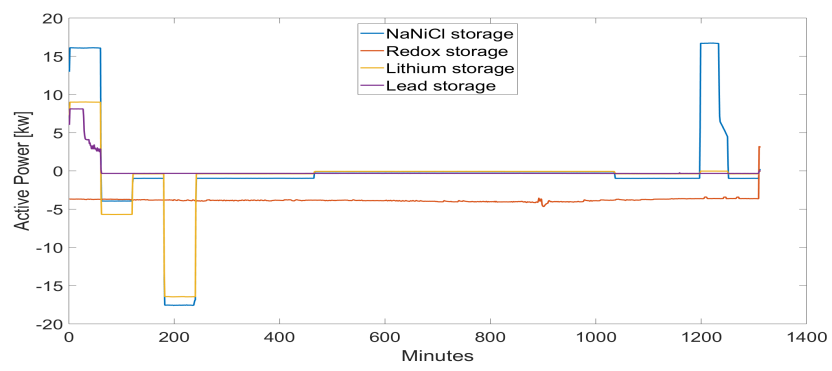

Fig. 5: Optimal charge/discharge plans for the storage units resulted from the optimization problem; scenario 2 . The positive/negative active power represents discharge/charge volumes respectively.

Similar to the Test 1, Fig. 6 and Fig. 7 illustrate the voltages and the frequencies of the micro-grid components for Test 2. Again, it is obvious that any issue related to the component voltages and the frequencies is not observed in Test 2 .

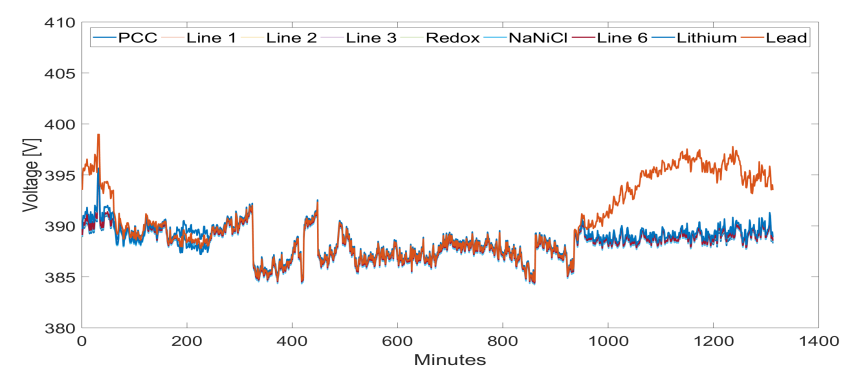

Fig. 6: Micro-grid component voltages for Test 2

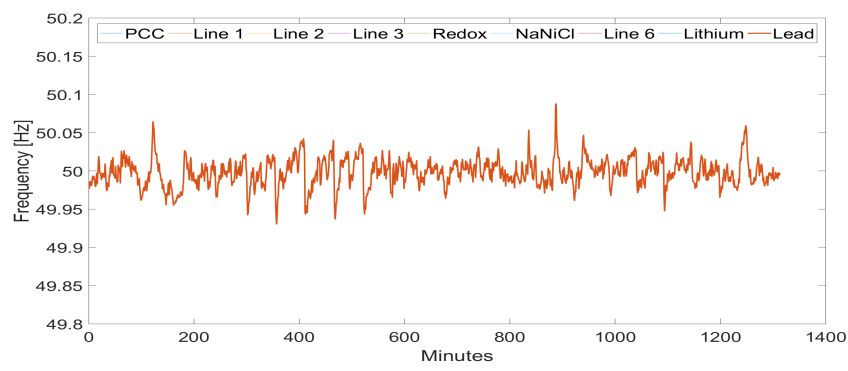

Fig. 7: Micro-grid component frequencies for Test 2.

\section{B. Tests constructed on the RSE's modified configuration:}

Test 3: The results using the modified configuration of the micro-grid, when the EES units are owed by an aggregator, are depicted in Fig. 8, Fig. 9 and Fig. 10. Fig. 8 illustrates the optimal charge/discharge plans for EES units resulting from the optimization model. While, Fig. 9 and Fig. 10 draw the voltages and the frequencies of the micro-grid components for Test 3. According to Fig. 9, this approach determines higher voltage variation respect to Test 1 and 2, but in any case the voltages are still within the bound for the entire period.

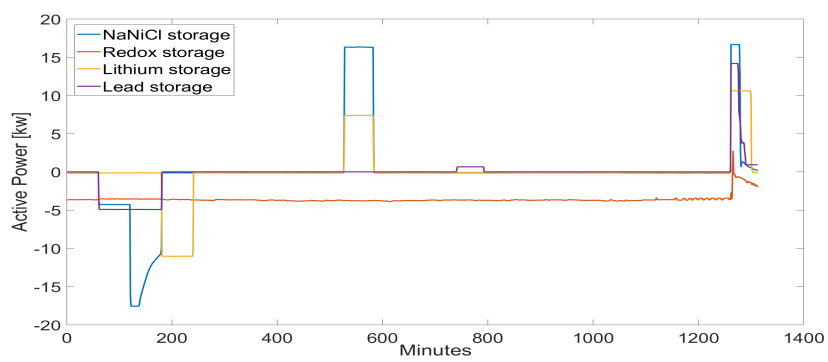

Fig. 8: Optimal charge/discharge plans for the storage units resulted from the optimization problem, scenario 1 . The positive/negative active power represents discharge/charge volumes respectively.

Test 4: Finally, the results obtained from Test 4 are presented in Fig. 8, Fig. 9 and Fig. 10, where the modified configuration of the micro-grid is used and it is assumed that the EES units are owed by the grid operator. In this specific case also the component voltages and frequencies lay within the allowable limits.

To summarise, according to the results gathered and analysed in all four tests, higher voltage variation has been discovered in Test 3 compared with the other three test 


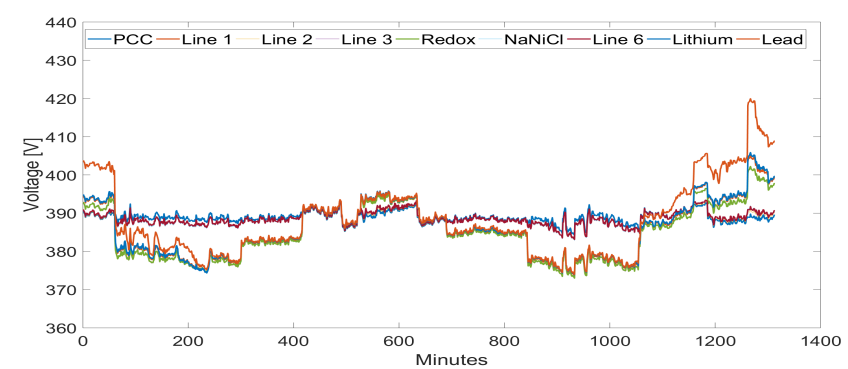

Fig. 9: Micro-grid component voltages for Test 3.

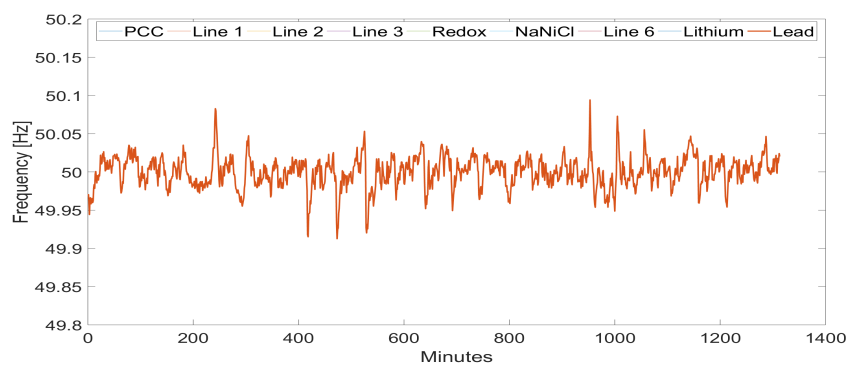

Fig. 10: Micro-grid component frequencies for Test 3.

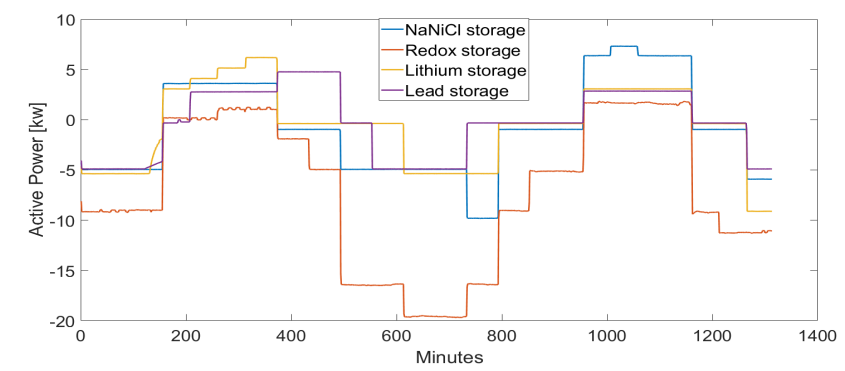

Fig. 11: Charge/discharge plans for the storage units to support the micro-grid needs The positive/negative active power represents discharge/charge volumes respectively.

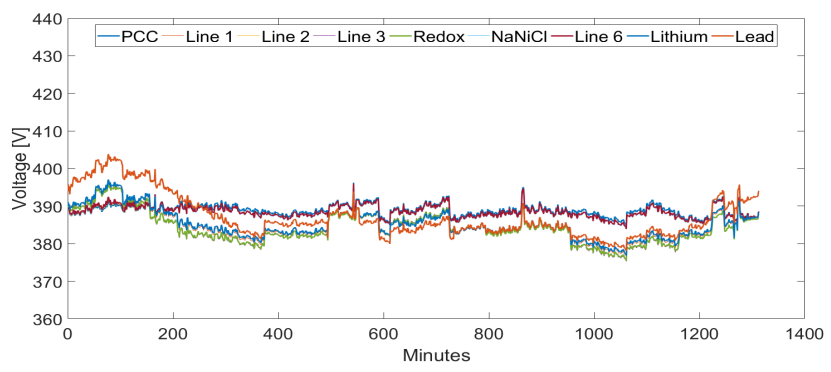

Fig. 12: Micro-grid component voltages for Test 4.

results. However, still component voltages in Test 3 don't violate the voltage limits. Thus, the present configuration of the RSE's micro-grid is strong enough to cope with current RES integration level and corresponding disturbances caused by intermittent RES units, namely PV and wind. Moreover, the RSE's current micro-grid configuration might support additional RES integration in the system without causing any voltage or frequency problem. More tests need to be launched and more analysis should be carried out to emphasise this

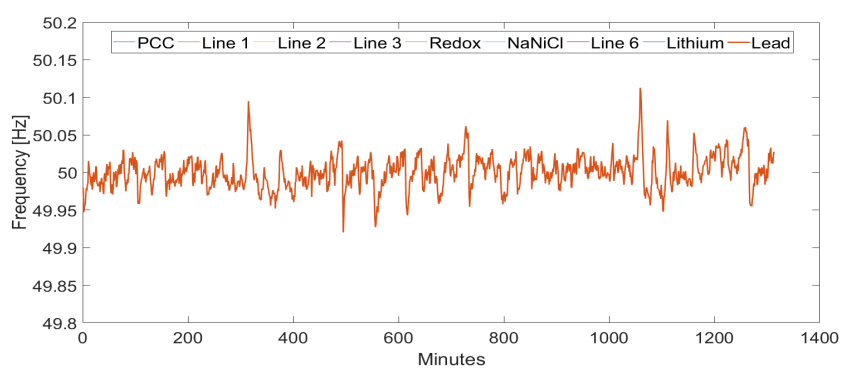

Fig. 13: Micro-grid component frequencies for Test 4.

thought.

\section{CONClusion}

The aggregators are required business entities, who enable smooth cooperation of large EES unit owners and the SO (System Operator) while maximizing their own profit. This paper constructs different test scenarios to investigate the integration of EES unit technologies in a micro-grid, when the EES units are owned by an aggregator or the grid owner. The RSE's micro-grid configuration has been used for performing tests. The assessment of the micro-grid behaviour is carried out through observations of frequencies and voltages of the underling grid components. The present configuration of the RSE's micro-grid is strong enough to cope with current RES integration level and corresponding disturbances caused by intermittent RES units. In addition, RSE's micro-grid configuration is quite robust to allow new level of integration of RES units. However, to be able to stress this opinion out more tests should be conducted.

\section{ACKNOWLEDGEMENTS}

This work has been carried out in the context of the EriGrid project, funded by the European Commission under the Horizon 2020, Grant agreement No. 654113 (https://erigrid.eu/).

\section{REFERENCES}

[1] “Energy roadmap 2050," European Commission, Tech. Rep., 2012.

[2] "Unlocking flexibility: Nordic tso discussion paper on third-party aggreggators," Energiner, Fingrid, Statnet, Svenska Kraftnet, Tech. Rep., 2017.

[3] "Global EV outlook: Understanding the electric vehicle landscape to 2020," International Energy Agency, Available at http://www.iea.org/ publications/globalevoutlook_2013.pdf, Tech. Rep., 2013.

[4] J. A. P. Lopes, F. J. Soares, and P. M. R. Almeida, "Integration of electric vehicles in the electric power system," Proc. IEEE, vol. 99, no. 1, pp 168-183, Jan 2011.

[5] Y. Vardanyan, F. Banis, S. Pourmousavi, and H. Madsen, "Optimal coordinated bidding of a profit-maximizing ev aggregator under uncertainty," in 5th IEEE International Energy Conference, June 2018.

[6] C. Sandroni, M. Verga, R. Lazzari, M. Fantini, M. Sacchi, and V. Prandoni, "RSE's microgrid: A facility for research, development and testing of future distributed generation and microgrid technologies," in AEIT International Annual Conference, 2016.

[7] Y. Vardanyan and M. Hesamzadeh, "The coordinated bidding of a hydropower producer in three-settlement markets with time-dependent risk measure,' Electric Power Systems Research, vol. 51, pp. 40-58, Oct. 2017.

[8] "Nord pool database," Available at http://www.nordpoolspot.com/. 